\title{
Interactions of Focal Cortical Lesions With Error Processing: Evidence From Event-Related Brain Potentials
}

\author{
Markus Ullsperger and D. Yves von Cramon \\ Max Planck Institute of Cognitive Neuroscience \\ and University of Leipzig
}

\author{
Notger G. Müller \\ Humboldt University
}

\begin{abstract}
Electrophysiological and hemodynamic studies have suggested that structures in the vicinity of the anterior cingulate cortex are involved in performance monitoring, particularly in detection of errors. Bidirectional interactions between the frontomedian system involved in performance monitoring and the lateral prefrontal cortex as well as the orbitofrontal cortex have been proposed, but few studies have directly addressed this issue. The authors used a speeded flankers task to investigate error-related event-related potentials in 3 patient groups with different focal cortical lesions. Whereas bilateral frontopolar lesions involving the orbitofrontal cortex as well as temporal lesions did not alter the error-related negativity (ERN), lesions of the lateral frontal cortex resulted in an abolition of the ERN and in a reduction of the error positivity.
\end{abstract}

For complex, goal-directed behavior, it is important to detect when actions are erroneous and to apply appropriate remedial mechanisms. These performance-monitoring functions have become a major focus of research over the past decade. Cumulative evidence, particularly from event-related potential (ERP) studies, gave rise to the error-detection model proposing an error-processing system made up of (a) a monitoring system that detects errors and (b) a remedial action system (cf. Coles, Scheffers, \& Holroyd, 1998; 2001; Falkenstein, Hoormann, Christ, \& Hohnsbein, 2000). The error-detection system has been suggested to compare the representations of the correct (appropriate and intended) and the actually performed response (Coles et al., 2001; Falkenstein et al., 2000; Falkenstein, Hohnsbein, Hoormann, \& Blanke 1990; Holroyd, 2001). When the system detects a mismatch between these representations, a negative-going ERP with a frontocentral maximum is elicited within about $80 \mathrm{~ms}$ after the response: the error negativity ( $\mathrm{Ne}$; Falkenstein et al., 1990) or error-related negativity (ERN; Gehring, Goss, Coles, Meyer, \& Donchin, 1993). The representation of the actual response appears to be derived from an efference copy that is sent to the monitoring system when the motor command is issued (Gehring et al., 1993). The correct (appropriate) response representation results from full evaluation of the stimuli and the application of the

Markus Ullsperger and D. Yves von Cramon, Max Planck Institute of Cognitive Neuroscience, Leipzig, Germany, and Day Clinic for Cognitive Neurology, University of Leipzig, Leipzig, Germany; Notger G. Müller, Department of Neurology, Charité, Humboldt University, Berlin, Germany.

We thank M. Brass for helpful comments on an earlier version of the article.

Correspondence concerning this article should be addressed to Markus Ullsperger, Max Planck Institute of Cognitive Neuroscience, P.O. Box 500 355, D-04303, Leipzig, Germany. E-mail: ullsperg@cns.mpg.de task-relevant stimulus-response mappings and decision criteria. In most studies investigating performance monitoring, the majority of errors were due to premature responses given before completion of stimulus evaluation (Coles et al., 2001). Thus, the representation of the correct response can still be derived from ongoing stimulus evaluation while the erroneous response is initiated. Holroyd and colleagues (Holroyd, 2001; Holroyd, Reichler, \& Coles, 1999) argued that the comparison process may involve the basal ganglia, a view supported by a recent study of error processing in Parkinson's disease (Falkenstein et al., 2001).

In addition to the ERN, a centroparietal positivity occurring about $300 \mathrm{~ms}$ after incorrect responses has repeatedly been described and named the error positivity (Pe; Falkenstein et al., 1990, 2000). Recent studies have suggested that the Pe may reflect the awareness of an error followed by the implementation of remedial actions (Davies, Segalowitz, Dywan, \& Pailing, 2001; Nieuwenhuis, Ridderinkhof, Blom, Band, \& Kok, 2001). On the basis of the finding that (in contrast to an unchanged ERN) the amplitude of the Pe was larger when error rates were high as compared with low, Falkenstein et al. (2000) argued that the Pe may also reflect a "subjective/emotional error assessment process, which is modulated by the individual significance of an error" (p. 104).

Evidence from electrophysiological as well as hemodynamic measures suggests that structures of the frontomedian wall, such as the anterior cingulate cortex (ACC) are active during error detection (e.g., Carter et al., 1998; Dehaene, Posner, \& Tucker, 1994; Holroyd, Dien, \& Coles, 1998; Kiehl, Liddle, \& Hopfinger, 2000). Recently, the functional anatomy of error processing was refined by the suggestion that the human homologue of the cingulate motor area (CMA) located in the ventral bank of the anterior cingulate sulcus generates the ERN (Holroyd, 2001). This view was supported by a combined functional magnetic resonance imaging (fMRI) and ERP study investigating the neural correlates of performance monitoring (Ullsperger \& von 
Cramon, 2001). It was shown that the homologue of the CMA was most engaged during error processing.

The conflict-monitoring theory (Botvinick, Braver, Barch, Carter, \& Cohen, 2001; Carter et al., 2000) differs to some extent from the error-detection model as described above. It suggests that the frontomedian cortices in the vicinity of the ACC "provide an on-line conflict signal, indicating the need to engage brain regions such as dorsolateral prefrontal cortex and inferior parietal cortex to implement strategic process" (Carter et al., 2000, p. 1947). However, concerning the generation of the ERN, the conflict-monitoring model provides assumptions similar to those of the error-detection model: It proposes that the CMA generates the ERN when "post-response conflict" arises, that is, when the representation of the actually performed response is in conflict with the appropriate response required by the task (Carter, 2001).

Although considerable knowledge about the error processing system has been gathered, its integration with other aspects of complex behavior and higher cognitive functions is still insufficient. The interplay of the frontomedian structures involved in error and performance monitoring with other cortices known to play important roles in complex cognitive functions is still poorly understood. Reciprocal influences among performance monitoring, affective and motivational processes, and control functions for resolving task requirements (task-set management) must be assumed to explain complex human behavior.

\section{Interactions With the Lateral Prefrontal Cortex}

Several lines of evidence have shown the significance of the lateral prefrontal cortex in working memory functions such as maintenance and manipulation of information (D'Esposito, Postle, \& Rypma, 2000; Goldman-Rakic, 1996; Gruber \& von Cramon, 2001; Müller, Machado, \& Knight, in press; Petrides, 1996). In addition, functional neuroimaging studies have suggested an important role of the lateral prefrontal cortex in dealing with conflicts and interference (e.g., Carter et al., 2000; Hazeltine, Poldrack, \& Gabrieli, 2000; MacDonald, Cohen, Stenger, \& Carter, 2000; Zysset, Müller, Lohmann, \& von Cramon, 2001). Furthermore, the functional connectivity of the prefrontal cortex with the ACC has been demonstrated in anatomical studies in primates (e.g., Barbas \& Pandya, 1989; Bates \& Goldman-Rakic, 1993) and in a study combining repetitive transcranial magnetic stimulation and positron emission tomography (PET; Paus, Castro-Alamancos, \& Petrides, 2000; see also Paus, 2001).

Therefore, it is conceivable that the lateral prefrontal cortex interacts with performance monitoring in several ways. First, the lateral prefrontal cortex seems to be involved in the maintenance and manipulation of the mapping of sensory attributes on a set of responses by decision criteria (i.e., the task set; cf. Rogers \& Monsell, 1995). In other words, it participates in task-set management processes (Zysset et al., 2001). These processes are required when response conflict must be resolved or remedial actions are necessary after errors; thus, they are closely linked to performance monitoring (Carter et al., 2000; Ullsperger \& von Cramon, 2001). Second, the representation of the correct response, which is formed by ongoing stimulus evaluation on the basis of the task set, must be held in working memory for the comparison process proposed by the errordetection model. Therefore, it can be hypothesized that dysfunctions of the lateral prefrontal cortex lead to (a) problems with remedial actions during response conflict or after errors and (b) problems with the representation of the correct (appropriate) response, which may reduce the ability to detect errors. In fact, a recent study by Gehring and Knight (2000) demonstrated that lesions of the lateral prefrontal cortex interact with the electrophysiological correlates of error processing. In these patients, electrical brain activity - particularly the frontocentral negativity-was the same after errors as after correct responses.

\section{Interactions With Orbitofrontal Cortices}

Recent studies (e.g., Luu, Collins, \& Tucker, 2000; Luu $\&$ Tucker, 2001) have suggested an interaction of error detection (involving the caudal ACC) with limbic and paralimbic structures such as the orbitofrontal cortex and the rostral division of the ACC. The ERN amplitude was larger in participants who experienced high levels of subjective distress during errors than in participants with low negative affect (Luu, Collins, \& Tucker, 2000). Furthermore, Tucker, Hartry-Speiser, McDougal, Luu, and deGrandpre (1999) provided evidence that potentials similar to the ERN are also generated in tasks that involve affective judgments. Recently, a close relationship between error processing and reward-related brain activity, particularly reinforcement learning, has been put forward (e.g., Holroyd, 2001; Holroyd et al., 1999; Schultz \& Dickinson, 2000). Clinical studies have shown that patients with bilateral lesions of the orbitofrontal cortex have problems with performance monitoring: They are unable to deal with positive and negative consequences of actions (reward and punishment) and uncertainty (Bechara, Damasio, Tranel, \& Damasio, 1997; Bechara, Tranel, Damasio, \& Damasio, 1996). A further study provided evidence that lesions of the anterior orbitofrontal cortex were sufficient to produce a hypersensitivity to rewards and an insensitivity to punishments in a gambling task, whereas working memory functions were unaffected (Bechara, Damasio, Tranel, \& Anderson, 1998).

An interesting question is which subprocesses of performance monitoring, particularly of error processing, are impinged on by orbitofrontal lesions. It seems conceivable that the detection of errors may induce an emotional response similar to that evoked by punishment. Therefore, it could be hypothesized that patients with orbitofrontal lesions develop an emotional insensitivity to their errors, although error detection itself may be intact. If the Pe reflects an emotional assessment of the error as proposed by Falkenstein et al. (2000), it may be reduced when the orbitofrontal cortex is damaged. The ERN as a correlate of error detection, however, may remain unaffected.

In contrast, two studies by Gehring and colleagues would suggest that the ERN also may be influenced by the sub- 
jective significance of an error. It was shown that the ERN amplitude for accuracy instructions was significantly bigger than under speed conditions (Gehring et al., 1993). In addition, the ERN amplitude was larger in individuals with obsessive-compulsive disorders than in matched controls and correlated with symptom severity (Gehring, Himle, \& Nisenson, 2000). It could be speculated that if errors lose their emotional significance after damage of the orbitofrontal cortex, the ERN might also be smaller.

The aim of the present study was to investigate the impact of lateral frontal, frontopolar-orbitofrontal, and temporal cortical lesions on the electrophysiological correlates of error processing, the ERN and the Pe, and thus to draw inferences on the functional role of the lesioned cortices in performance monitoring.

In patients with unilateral prefrontal cortex lesions, a replication of the findings reported by Gehring and Knight (2000) was expected - that is, similar waveforms of the response-locked ERPs in the time range of $0-100 \mathrm{~ms}$ after the response (i.e., the time range of the ERN) for correct and error trials. In addition, the present study aimed at extending these results by investigating the Pe, which had not been examined in this patient group before. If the ability to distinguish between correct and incorrect responses is compromised because of the lesion of the lateral frontal cortex, this might be reflected by a reduction or abolition of the Pe, because compromised error detection may also lead to problems with awareness and assessment of errors.

As pointed out above, in patients whose orbitofrontal and frontopolar cortex were damaged bilaterally, several hypotheses are plausible. If the Pe reflects an emotional assessment of errors, it should be reduced in amplitude in these patients On the other hand, findings by Falkenstein et al. (2000) would predict the ERN should be unaffected, and on the basis of the study of Gehring et al. (1993), an amplitude reduction of the ERN could be anticipated.

To our knowledge, no evidence for an involvement of temporal cortices in performance monitoring has been reported to date. Therefore, no specific hypotheses can be formulated for these patients who served as clinical controls.

\section{Method \\ Participants}

Three patient groups with different localized lesions took part in the study: (a) a group with unilateral lesions centered in the lateral frontal cortex ( $n=7$, mean age 50.7 years, $S D=11.3$ ), (b) a group with bilateral frontopolar lesions involving the orbitofrontal cortex ( $n=6$, mean age 38.8 years, $S D=9.5$ ), and (c) a group with unilateral temporal lesions $(n=6$, mean age 38.4 years, $S D=11.7)$. Demographic data, lesion side, description, and etiology are shown in Table 1. For illustration, T2 weighted magnetic resonance images of the lesions are depicted in Figure 1. Two healthy control groups, a younger $(n=9$, mean age 38.4 years, $S D=8.9)$ and an older $(n=9$, mean age 51.1 years, $S D=8.5)$, participated in the study. The younger control group was age matched with the bifrontopolar and the temporal lesion groups, whereas the older control group was age matched with the patients with lateral frontal cortex lesions.
Informed consent was obtained from each participant before testing. The experiments complied with German legal requirements. Patients and control persons were paid for their participation.

\section{Task}

A speeded modified flankers task known to produce response conflict and to yield high error rates was used (cf. Kopp, Rist, \& Mattler, 1996). Participants had to respond as fast and as accurately as possible to a target arrow briefly presented in the center of the screen. When the target pointed to the right, the right button was to be pressed, and when the target pointed to the left, response with the left button was required. The target arrow was preceded by irrelevant flankers (arrows or neutral signs) displayed above and below the screen center. Thus, first the flankers appeared on the screen for $100 \mathrm{~ms}$; then the target arrow was added to the picture. After another $30 \mathrm{~ms}$, a blank screen was presented. The arrows were $0.46^{\circ}$ tall and $1.08^{\circ}$ wide, and the four flankers were presented $0.52^{\circ}$ and $1.04^{\circ}$ above and below the screen center. Flankers could point in the same direction as the target arrow (compatible trials, $30 \%$ of trials), in the opposite direction as the target arrow (incompatible trials, $30 \%$ of trials), or could have no direction information (neutral trials, $30 \%$ of trials). Compatible, incompatible, and neutral trials appeared in randomized order. When participants did not respond within $700 \mathrm{~ms}$, a feedback ("respond faster") appeared on the screen for $710 \mathrm{~ms}$; otherwise, the screen remained blank. The trial duration amounted to 1,540 ms. A total of 720 trials were presented, with five short breaks after each 120 trials.

\section{ERP Data Collection}

Participants were seated in a dimly lit, electrically shielded chamber. The electroencephalograph (EEG) activity was recorded with $\mathrm{Ag} / \mathrm{AgCl}$ electrodes mounted in an elastic cap (Electrocap International, Eaton, $\mathrm{OH}$ ) from 29 scalp sites of the 10-20 system. Electrode labeling was based on the standard nomenclature described in Sharbrough et al. (1990). The ground electrode was positioned $10 \%$ of the distance between the two preocular points right to $\mathrm{Cz}$. The vertical electrooculogram (EOG) was recorded from electrodes located above and below the right eye. The horizontal EOG was collected from electrodes positioned at the outer canthus of each eye. Electrode impedance was kept below $5 \mathrm{k} \Omega$. The right mastoid was recorded as an additional channel. All scalp electrodes were referenced to the left mastoid and were re-referenced off line to linked mastoids. The EEG and EOG were recorded continuously with a band pass from DC to $30 \mathrm{~Hz}$ and were A-D converted with 16-bit resolution at a sampling rate of $250 \mathrm{~Hz}$ and stored on hard disc and CD-ROM for off-line analysis.

\section{ERP Data Analysis}

In a first step, the EEG epochs were scanned for muscular and large EOG artifacts. Whenever the standard deviation in a 200-ms interval exceeded $50 \mu \mathrm{V}$, the epoch was rejected. In a second step, small horizontal and vertical EOG artifacts that were still present in the EEG signal were corrected by an eye movement correction procedure (Pfeifer, 1993) based on a linear regression method described by Gratton, Coles, and Donchin (1983). Finally, ERPs were separately averaged for correct and erroneous responses on incompatible trials and for correct responses on compatible trials (there were too few errors on compatible trials to obtain reliable ERPs from these trials). Late responses followed by the feedback "respond faster" were excluded from the average. The epochs were response locked and lasted from $100 \mathrm{~ms}$ before to $500 \mathrm{~ms}$ after the 
Table 1

Demographic and Lesion Data of the Three Patient Groups

\begin{tabular}{cccccl}
\hline Patient ID & Sex & $\begin{array}{c}\text { Age at test } \\
\text { (years) }\end{array}$ & $\begin{array}{c}\text { Side of } \\
\text { lesion }\end{array}$ & Etiology & \multicolumn{1}{c}{ Description of lesion } \\
\hline & \multicolumn{5}{c}{ Lateral frontal group } \\
102 & M & 50 & L & MCAI & Frontolateral, anterior insula \\
120 & M & 51 & R & MCAI & Frontolateral, insula, anterior temporolateral \\
237 & M & 60 & L & MCAI & Frontolateral, anterior insula \\
325 & M & 39 & L & AVM & Frontolateral, anterior insula \\
369 & F & 47 & L & MCAI & Frontolateral, anterior insula \\
370 & M & 38 & R & TBI & Frontolateral, anterior temporolateral \\
403 & M & 70 & L & MCAI & Frontolateral \\
\hline
\end{tabular}

Bifrontopolar-orbitofrontal group

\begin{tabular}{llllll}
150 & M & 26 & B & TBI & Frontopolar, orbitofrontal \\
203 & F & 49 & B & TU & Frontopolar, orbitofrontal $^{\text {a }}$ \\
291 & M & 38 & B & TBI & Frontopolar, orbitofrontal $^{26}$ \\
300 & M & 39 & B & TBI & Frontopolar, orbitofrontal \\
330 & M & 50 & B & TBI & Frontopolar, orbitofrontal \\
342 & M & 31 & B & TBI & Frontopolar, orbitofrontal \\
\hline
\end{tabular}

Temporal group

\begin{tabular}{|c|c|c|c|c|c|}
\hline 148 & $\mathrm{~F}$ & 46 & $\mathrm{R}$ & AN & Anterior temporolateral $^{\mathrm{b}}$ \\
\hline 252 & M & 45 & $\mathrm{~L}$ & TU & Anterior temporolateral ${ }^{\mathrm{c}}$ \\
\hline 315 & $\mathrm{~F}$ & 38 & $\mathrm{~L}$ & HSE & Anterior temporolateral, insula \\
\hline 317 & $\mathrm{~F}$ & 55 & $\mathrm{~L}$ & TBI & Anterior temporolateral \\
\hline 328 & M & 38 & $\mathrm{R}$ & MCAI & $\begin{array}{l}\text { Posterior temporolateral, insula, } \\
\text { occipitolateral, parietal operculum }\end{array}$ \\
\hline 372 & M & 25 & $\mathrm{~L}$ & VI & Anterior temporolateral $^{\mathrm{d}}$ \\
\hline
\end{tabular}

Note. $\quad \mathrm{ID}=$ identification number; $\mathrm{M}=$ male; $\mathrm{F}=$ female; $\mathrm{L}=$ left $\mathrm{R}=$ right; $\mathrm{B}=$ bilateral; MCAI = middle cerebral artery infarction; $\mathrm{AVM}=$ arteriovenous malformation; $\mathrm{TBI}=$ traumatic brain injury; $\mathrm{TU}=$ tumor; $\mathrm{AN}=$ aneurysm; HSE = herpes simplex encephalitis; $\mathrm{VI}=$ venous infarction.

${ }^{a}$ After resection of meningioma in the olfactory groove. ${ }^{\mathrm{b}}$ Ruptured aneurysm of right middle cerebral artery, spasm of M2. ${ }^{\mathrm{c}}$ After resection of astrocytoma up to $6 \mathrm{~cm}$ posterior from temporal pole. ${ }^{\mathrm{d}}$ VI following TBI.

response button press. The average voltages in the $100 \mathrm{~ms}$ preceding the response onset served as a baseline. Mean amplitude measures in given time windows (centered around the peaks of the ERN and the $\mathrm{Pe}$ ) at the electrodes that spanned the region where the ERN and Pe are largest (F3, Fz, F4, FC3, FCz, FC4, C3, Cz, C4, P3, Pz, P4) were used for statistical analysis. Lateral electrodes for individuals from the temporal and the lateral frontal groups with lesions on the right side were switched so that F3, FC3, C3, and P3 corresponded to the side ipsilateral to the lesion (e.g., cf. Gehring \& Knight, 2000). Because most errors were made on incompatible trials, the analysis of error processing was restricted to the comparison of correct and error trials within the incompatible condition. By subjecting the data to mixed-type analyses of variance (ANOVAs) with the between-subjects factor Group (two levels) and the within-subjects factors Response Type (two levels), Anterior-Posterior Dimension (four levels), and Lateral Dimension (three levels), data were tested as to whether or not the ERP amplitudes differed between correct and erroneous trials. Further, to test whether the ERPs were topographically different, the same ANOVA was conducted after rescaling such that amplitude differences between the two contrasted conditions were removed (McCarthy \& Wood, 1985). All effects with more than one degree of freedom in the numerator were adjusted for violations of sphericity according to the formula of Huynh and Feldt (1970). To avoid reporting large amounts of statistical results not relevant for the issues under investigation, only main effects or interactions, including the Response Type factor, are reported here. Topographic scalp potential maps were generated using a two-dimensional spherical spline interpolation (Perrin, Pernier, Bertrand, \& Echallier, 1989) and a radial projection from $\mathrm{Cz}$, which respects the length of the median arcs.

In studies investigating the ERN, prestimulus and preresponse baselines were shown to differ between correct and incorrect responses (Hohnsbein, Falkenstein, \& Hoormann, 1998; Morgan, Wenzl, Lang, Lindinger, \& Deeke, 1992); therefore, a second analysis was conducted in which the baseline problem was avoided by measuring the amplitudes as the difference between the preceding positive peak and the peak of the ERN or the negativity following correct responses, respectively (cf. Falkenstein et al., 2000; Kopp et al., 1996). These amplitude measures at FCz were subjected to ANOVAs with the between-subjects factor Group (two levels) and the withinsubjects factor Response Type (two levels). We also obtained peak latencies of the ERN at $\mathrm{FCz}$ with respect to the response.

Results

\section{Behavioral Data}

\section{Lateral Frontal Group}

Error rates did not differ significantly between the patient group with lateral frontal lesions $(M=11.62 \%, S E M=$ 

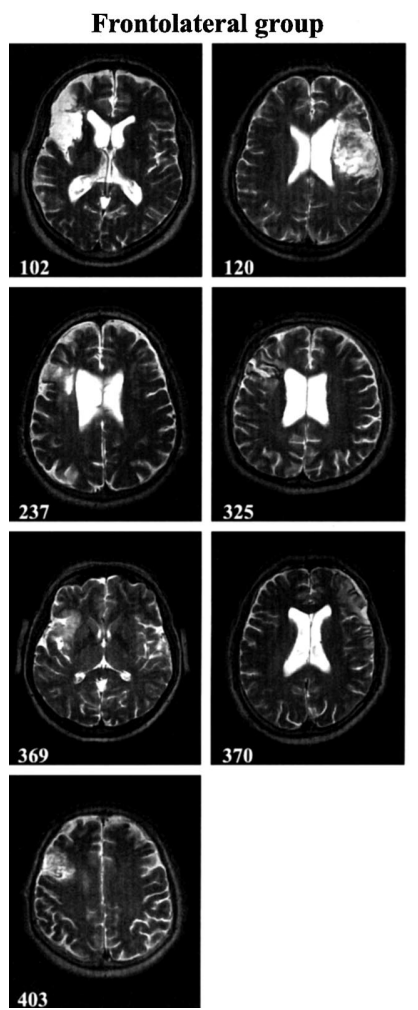
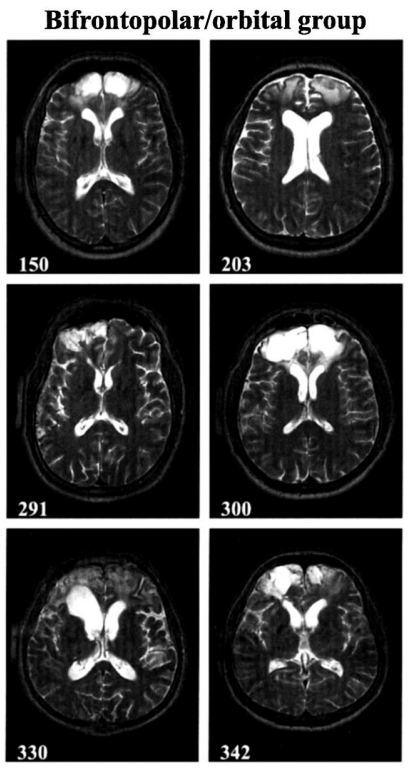
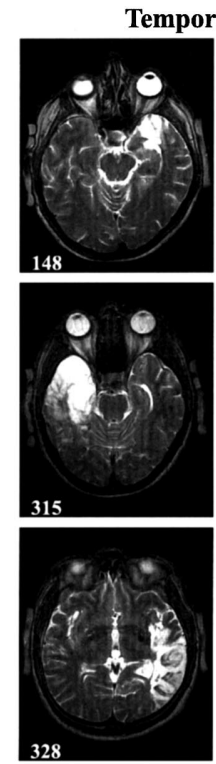
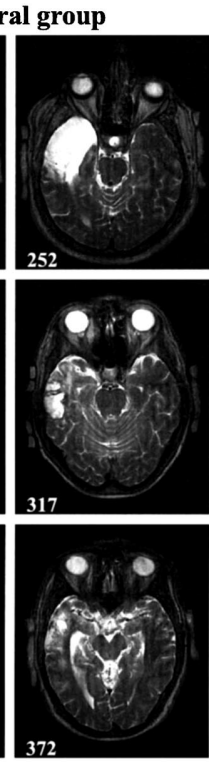

Figure 1. Axial slices of T2 weighted magnetic resonance images of each patient. The left hemisphere is oriented to the left on each image.

4.05) and the older control group $(M=7.99 \%, S E M=$ $3.04) ; t(14)=.73, p>.47$. The reaction times (RTs) on correct and incorrect responses were longer in the patient group (for correct, $M=457.8 \mathrm{~ms}, S E M=12.8$; for incorrect, $M=359.8 \mathrm{~ms}, S E M=18.8$ ) than in controls (for correct, $M=405.3 \mathrm{~ms}, S E M=13.1$; for incorrect, $M=$ $306.8 \mathrm{~ms}, S E M=8.1$ ). This impression was confirmed by an ANOVA with the between-subjects factor Group (two levels) and the within-subjects factor Response Type (two levels), which revealed a main effect of group, $F(1$, $14)=9.84, p<.01$, and a main effect of response type, $F(1,14)=140.87, p<.01$, but no interaction of these factors $(p>.90)$. The rate of late responses was significantly higher in the patient group $(M=12.1 \%, S E M=4.8)$ than in the controls $(M=0.8 \%, S E M=0.2, p<.05)$.

\section{Bifrontopolar Group}

Error rates were comparable across the two respective patient groups (for bifrontopolar, $M=7.85 \%, S E M=1.63$; for temporal, $M=4.88 \%, S E M=1.10$ ) and the young control group $(M=5.93 \%, S E M=0.99)$. $t$ tests revealed no significant difference in error rates between the bifrontopolar patients and controls $(p>.30)$ or between the temporal group and the controls $(p>.50)$. The RTs of the patients with bifrontopolar lesions (for correct, $M=406.5 \mathrm{~ms}$, $S E M=16.7$; for incorrect, $M=313.8, S E M=12.4)$ were not significantly different from those of the control persons (for correct, $M=383.4 \mathrm{~ms}, S E M=6.1$; for incorrect, $M=$ $295.4 \mathrm{~ms}, S E M=8.9$ ) as revealed by an ANOVA with the factors Group (2 levels, between subjects) $\times$ Response Type (2 levels, within subjects): No main effect of Group $(p>.14)$ and no interaction with the Group factor $(p>$ .70) were obtained. A main effect for Response Type was revealed, $F(1,13)=160.42, p<.01$, reflecting that in both groups the correct responses were slower than errors. The late response rate was $M=9.8 \%(S E M=7.4)$ in the bifrontopolar patient group and $M=0.8 \%(S E M=0.3)$ in the controls. However, the variance across the patients was very high in this regard; thus, the difference in late responses between the groups was not significant $(p=.26)$.

\section{Temporal Group}

Patients with temporal lobe lesions showed a tendency to respond slower than the age-matched controls (RT correct, $M=411.7 \mathrm{~ms}, S E M=16.0$; RT incorrect, $M=320.7$, $S E M=15.1)$. The ANOVA gave rise to an almost significant main effect of group, $F(1,13)=3.42, p=.09$, and a significant main effect of response type, $F(1,13)=235.89$, $p<.01$. The temporal lobe patients showed a trend of producing more late responses $(M=3.2 \%, S E M=1.1)$ than the controls $(p=.07)$. 


\section{Compatibility Effects}

To validate whether the different groups performed the task normally, the flanker compatibility effect was investigated. The distribution of error rates as well as the RTs for correct trials across the compatibility conditions are shown in Table 2. All patient groups showed the same compatibility effects as the control groups: Error rates and RTs were higher for incompatible than for compatible trials, and neutral trials were in between. We tested these findings using repeated-measure ANOVAs with the within-subjects factor Compatibility (three levels) and the between-subjects factor Group. The ANOVA for the frontolateral lesion patients and their controls gave rise to a main effect of Compatibility, $F(2,28)=17.2, p<.01$, and no significant Compatibility $\times$ Group interaction $(p=.73)$. The same findings were revealed by the ANOVAs for the bifrontopolar lesion group and their controls, main effect of Compatibility, $F(2$, 26) $=43.77, p<.01$ and of Compatibility $\times$ Group, $p=$ .93 , as well as for the temporal lesion patients and the corresponding controls, main effect of compatibility, $F(2$, $26)=42.17, p<.01$, and of Compatibility $\times$ Group, $p=.32$.

No significant effect of previous errors on accuracy or RTs in following trials was found in any of the patient or control groups. This was probably due to insufficient statistical power and the specific task.

\section{ERP Results}

The grand mean waveforms of the ERPs for compatible correct, incompatible correct, and incompatible erroneous

Table 2

Error Rates and Reaction Times (RTs) on Correct Trials for Compatible, Neutral, and Incompatible Trials

\begin{tabular}{|c|c|c|c|c|}
\hline \multirow[b]{2}{*}{ Group } & \multicolumn{2}{|c|}{ Error rate $(\%)$} & \multicolumn{2}{|c|}{ RT (ms) } \\
\hline & $M$ & SEM & $M$ & SEM \\
\hline \multicolumn{5}{|c|}{ Compatible trials } \\
\hline Frontolateral & 3.13 & 1.13 & 424.0 & 15.3 \\
\hline Older controls & 0.94 & 0.69 & 360.7 & 11.6 \\
\hline Bifrontopolar & 2.71 & 1.13 & 373.5 & 15.6 \\
\hline Temporal & 0.54 & 0.21 & 363.5 & 14.9 \\
\hline Younger controls & 1.15 & 0.41 & 339.1 & 4.8 \\
\hline \multicolumn{5}{|c|}{ Incompatible trials } \\
\hline Frontolateral & 22.77 & 8.06 & 492.5 & 19.2 \\
\hline Older controls & 19.90 & 6.57 & 459.0 & 12.4 \\
\hline Bifrontopolar & 16.67 & 3.21 & 445.5 & 17.8 \\
\hline Temporal & 11.22 & 1.80 & 462.3 & 18.0 \\
\hline Younger controls & 14.61 & 2.66 & 432.9 & 9.1 \\
\hline \multicolumn{5}{|c|}{ Neutral trials } \\
\hline Frontolateral & 8.97 & 3.45 & 459.9 & 13.3 \\
\hline Older controls & 3.13 & 2.05 & 408.4 & 13.1 \\
\hline Bifrontopolar & 4.17 & 1.39 & 408.3 & 17.5 \\
\hline Temporal & 2.90 & 1.44 & 414.9 & 17.4 \\
\hline Younger controls & 2.05 & 0.54 & 385.9 & 6.0 \\
\hline
\end{tabular}

trials are depicted in Figure 2 for each group; the scalp topographies in the time window of the ERN are shown in Figure 3.

\section{Frontolateral Group}

For the patient group with lateral prefrontal lesions, there was a negative peak-the ERN-on incompatible errors as well as a negative peak of similar size on compatible correct responses. The negativity on correct incompatible trials was larger than the ERN (Figure 2, left panel). In contrast, in the corresponding age-matched control group, the ERN had a larger amplitude than the negative deflection on correct (incompatible and compatible) trials. In both groups, in a later time range, from about $300 \mathrm{~ms}$ to $450 \mathrm{~ms}$ after the response, a positive deflection - the $\mathrm{Pe}$ - was found on error trials, however strongly reduced in the patient group. The mean peak latency of the ERN was $78.2 \mathrm{~ms}(S E M=6.3)$ in the frontolateral group and $78.7 \mathrm{~ms}(S E M=5.6)$ in the controls. A $t$ test revealed no significant latency differences between the groups $(p>90)$. To investigate differences in error processing, the amplitude data from the incompatible trials during an early and a late time window (capturing the ERN and the Pe time ranges) were subjected to mixed ANOVAs with the between-subjects factor Group and the within-subjects factor Response Type (correct, incorrect) and the topographical factors Anterior-Posterior Dimension and Lateral Dimension. The significant results are reported in Table 3 (upper panel).

The ERN. In the early time window, a significant interaction of Response Type $\times$ Group was obtained. Inspection of the ERPs suggests that this interaction reflects a reduction of the ERN amplitude in frontolateral patients, whereas the negativity on correct incompatible trials is unchanged with respect to the control group. To test this notion, separate ANOVAs were calculated comparing the ERPs for each response type between the two groups. Although no significant group effect was found for incompatible correct trials, a trend for a main effect of group was observed for erroneous trials, $F(1,14)=3.12, p<.10$. Furthermore, separate ANOVAs contrasting correct and erroneous incompatible trials were performed for each group. Although no response type effect was present in the frontolateral lesion group, the age-matched controls showed a trend for an ERP amplitude difference between correct and incorrect responses in the early time window, $F(1,8)=4.45, p<.10$.

To investigate the effect of flanker compatibility (reflecting response conflict and uncertainty) on response monitoring, we subjected the ERP data from correct compatible and correct incompatible trials to an ANOVA with the factors Group, Compatibility, Anterior-Posterior Dimension, and Lateral Dimension. A significant interaction of Compatibility and Anterior-Posterior Dimension was revealed, $F(3$, $42)=6.44, p<.01$; furthermore, there was a trend for a main effect of compatibility, $F(1,14)=3.14, p<.05$, reflecting a larger amplitude of the negativity on incompatible corrects as compared with compatible ones. Post hoc tests revealed the largest difference at frontocentral electrodes, $F(1,28)=5.06, p<.05$. To test whether the 

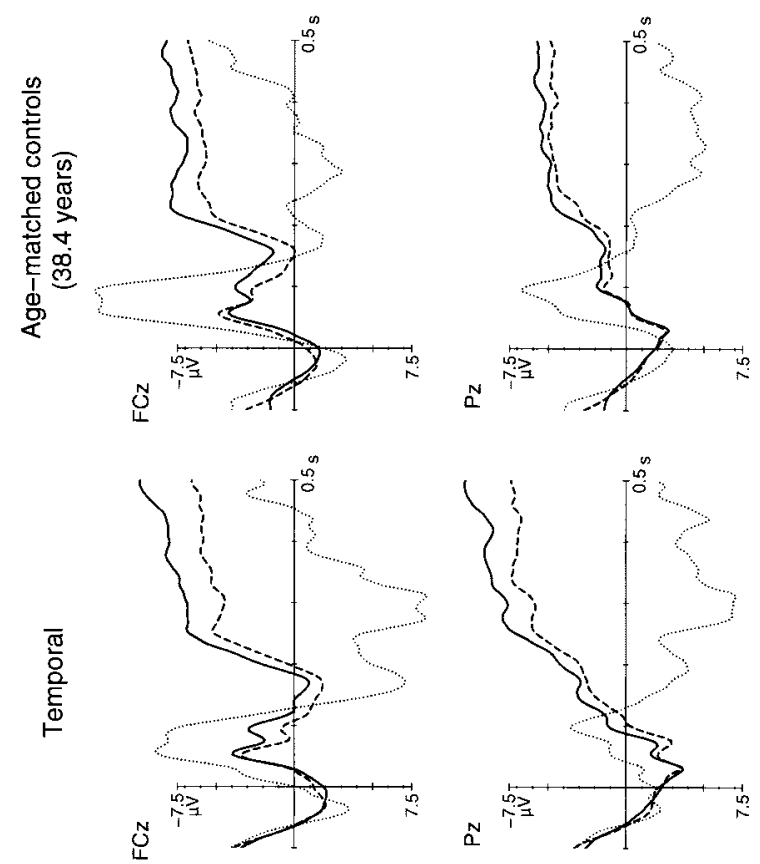

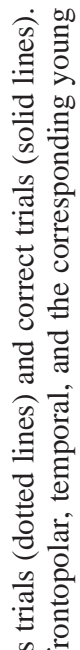
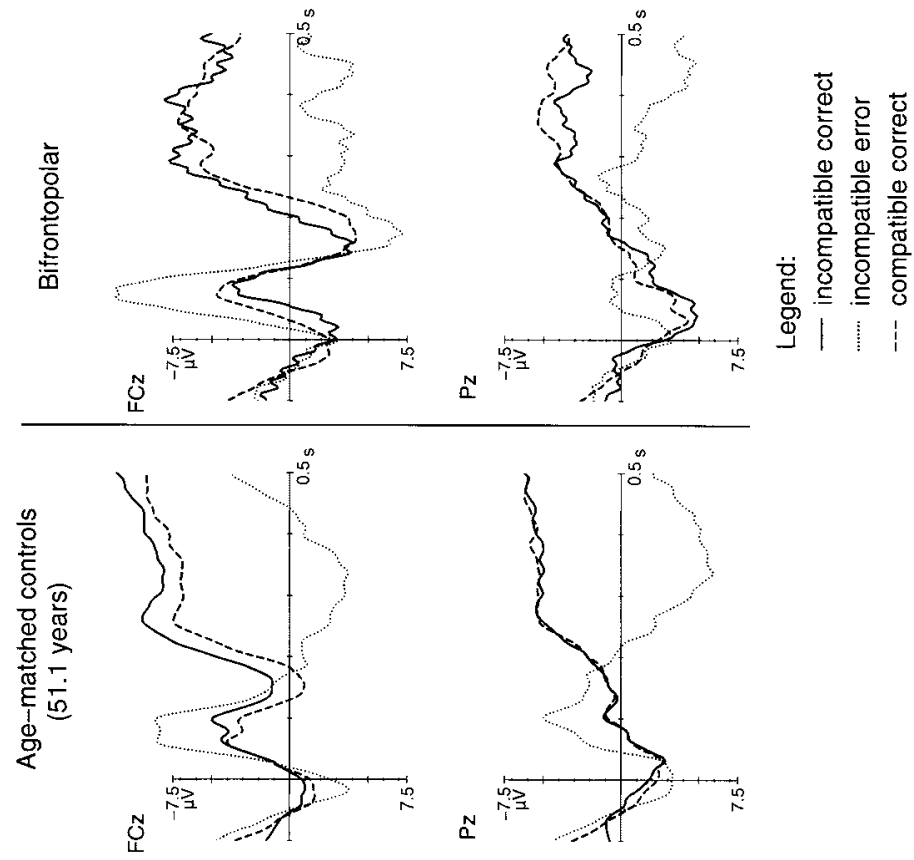

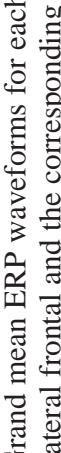

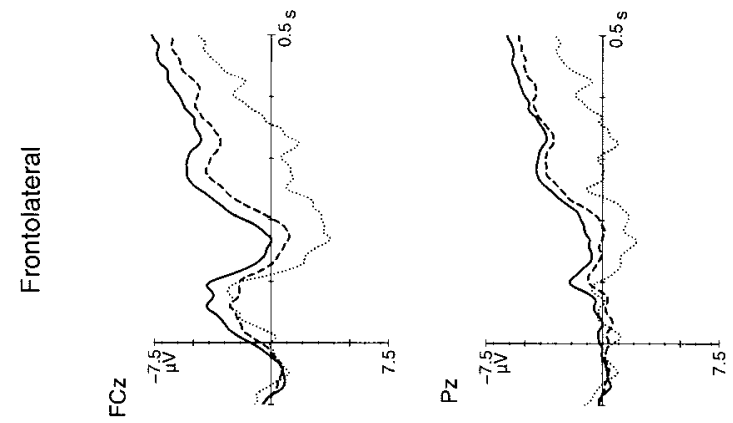

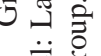

ن 夰

을

这齿 


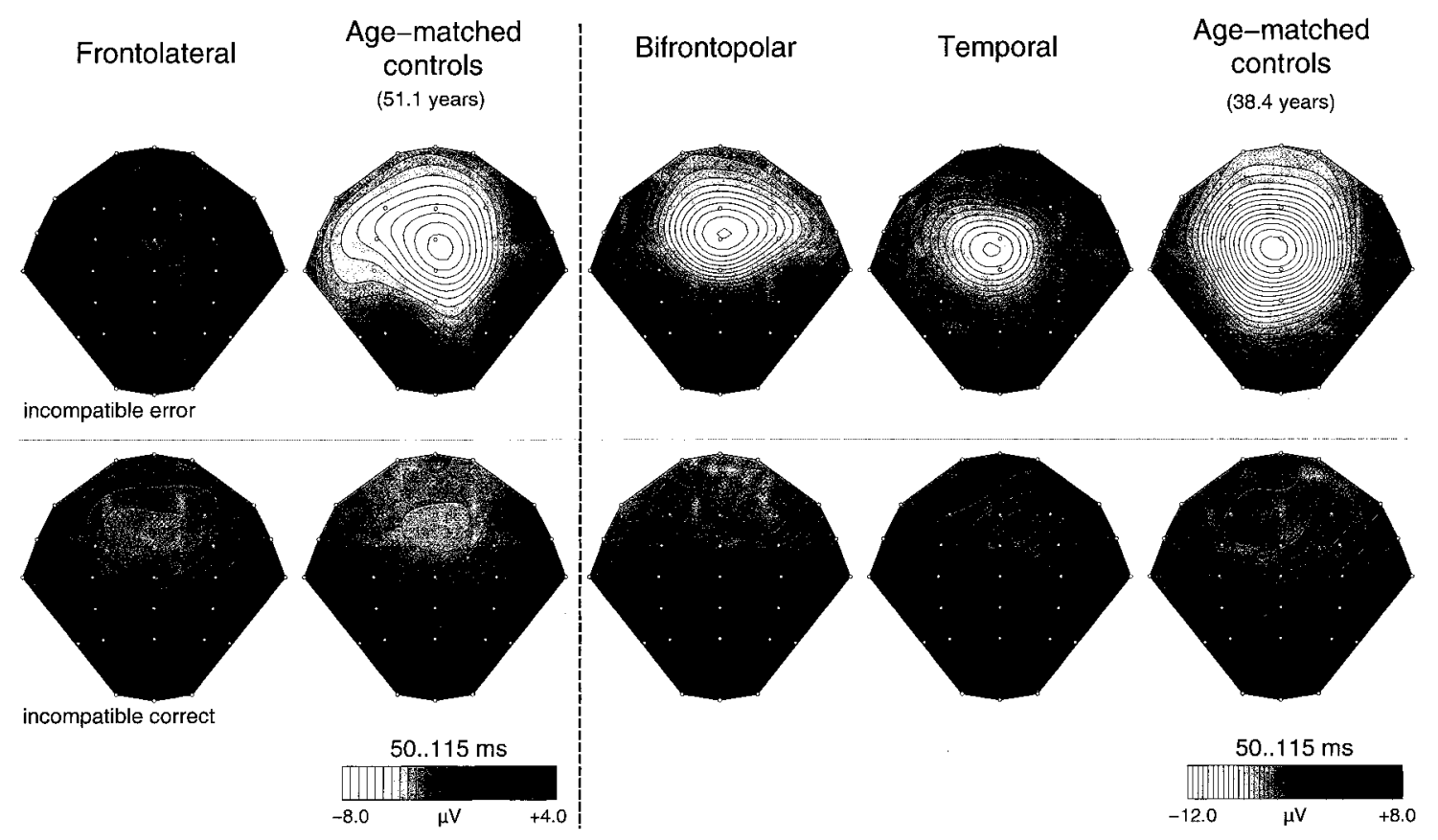

Figure 3. Topographical scalp potential distribution from each group in a time range from $50 \mathrm{~ms}$ to $115 \mathrm{~ms}$ after errors (upper row) and correct responses (lower row). Left panel: Lateral frontal and the corresponding older control group. Right panel: Bifrontopolar, temporal, and the corresponding young control group. Anterior direction: Top.

interaction with Anterior-Posterior Dimension reflected a topographical difference, the same ANOVA was performed on the amplitude-normalized data (McCarthy \& Wood, 1985), revealing a significant interaction of Compatibility $\times$ Anterior-Posterior Dimension, $F(3,42)=18.48, p<.01$.

Peak amplitudes at $F C z$. The amplitudes of the negativity following the response at $\mathrm{FCz}$ measured relative to the preceding positive peak are depicted on Figure 4. As pointed out in the Method section, this measurement of the ERN peak amplitude avoids the baseline problem (Falkenstein et al., 2000; Kopp et al., 1996). To contrast the ERN on erroneous and the negativity on correct incompatible trials, an ANOVA was performed with the factors Group and Response Type. It gave rise to a significant main effect of Response Type, $F(1,14)=10.83, p<.01$, and a Response Type $\times$ Group interaction, $F(1,14)=7.24, p<$ .05. This interaction was examined using the Tukey honestly significant difference test performed on an alpha level of .05. Although the amplitude of the negativity on correct incompatible trials did not differ significantly between groups (frontolateral patients, $M=6.12 \mu \mathrm{V}$; controls, $M=7.24 \mu \mathrm{V}$; minimum significant difference $=5.13)$, the ERN was significantly larger in the control group than in the frontolateral patients (frontolateral patients, $\mathrm{M}=6.86 \mu \mathrm{V}$; controls, $\mathrm{M}=14.62 \mu \mathrm{V}$; minimum significant difference $=7.67$ ). Moreover, separate follow-up ANOVAs for each group revealed a significant main effect of Response Type in the control group, $F(1,8)=18.44, p<.01$, but no such effect in the frontolateral patient group $(p>.68)$. These results suggest that when the lateral prefrontal cortex was damaged, the ERN was reduced to the amplitude of the negativity following correct responses. In separate ANOVAs, we also tested the influence of Compatibility on the amplitude of the negativity following correct responses. There was a main effect of Compatibility found for the patient group, $F(1,6)=7.96, p<.03$, suggesting that the amplitude on incompatible trials was larger than on compatible ones. This effect was absent for the controls $(p>.20)$.

The Pe. The ANOVA contrasting the ERPs for correct and erroneous incompatible trials in the late time window revealed a main effect of Response Type, reflecting that in both groups a Pe was present on erroneous trials (cf. Table 3, upper panel). This fact was supported by ANOVAs performed separately for both groups revealing significant main effects of Response Type: frontolateral group, $F(1$, $8)=16.42, p<.01$; controls, $F(1,8)=41.24, p<.01$. Moreover, the Response Type $\times$ Group interaction and a trend for the Response Type $\times$ Lateral Dimension interaction were found. The follow-up ANOVA for correct incompatible trials revealed neither a main effect of nor an interaction with the factor Group, suggesting that the late ERPs on correct trials did not differ significantly between frontolateral patients and their controls. In contrast, the ANOVA for erroneous trials gave rise to a main effect of group, $F(1$, $14)=4.80, p<.05$, reflecting that the Pe was present in both groups but lower in amplitude for the patients. Post hoc contrasts were performed to examine the interaction with Lateral Dimension and revealed that in both groups, the ERPs in the late time window differed most at midline 
Table 3

Results of the Mixed Analysis of Variance Performed for the Mean Amplitude Measures

\begin{tabular}{|c|c|c|c|c|}
\hline \multirow[b]{2}{*}{ Factor } & \multicolumn{2}{|c|}{$50-115 \mathrm{~ms}$} & \multicolumn{2}{|c|}{$300-450 \mathrm{~ms}$} \\
\hline & $d f$ & $F$ & $d f$ & $F$ \\
\hline
\end{tabular}

Frontolateral group versus older controls

\begin{tabular}{lcccc} 
Group & - & - & $\overline{-}$ & $\overline{-}$ \\
Response & - & - & 1,14 & $50.36^{* * *}$ \\
Response $\times$ Group & 1,14 & $4.74 * *$ & 1,14 & $8.83^{* *}$ \\
Response $\times$ Lateral & - & - & 2,28 & $3.66^{*}$ \\
\hline
\end{tabular}

Bifrontopolar group versus young controls

\begin{tabular}{lcccc} 
Group & $\overline{-}$ & $\overline{-}$ & - & - \\
Response & 1,13 & $12.98^{* * *}$ & 1,13 & $33.23^{* *}$ \\
Response $\times$ Group & - & - & - & - \\
$\begin{array}{l}\text { Response } \times \text { Ant/Post } \\
\text { Response } \times \text { Ant/Post }\end{array}$ & 3,39 & $5.50^{* *}$ & - & - \\
$\quad \times$ Group & - & - & 3,39 & $4.00^{* *}$ \\
$\begin{array}{l}\text { Response } \times \text { Lateral } \\
\text { Response } \times \text { Ant/Post }\end{array}$ & 2,26 & $17.29 * * *$ & - & - \\
$\quad \times$ Lateral & 6,78 & $6.55^{* * *}$ & - & - \\
\hline
\end{tabular}

Temporal group versus young controls

\begin{tabular}{|c|c|c|c|c|}
\hline Group & - & - & - & - \\
\hline Response & 1,13 & $5.56 * *$ & 1,13 & $30.57 * * *$ \\
\hline Response × Group & - & - & - & - \\
\hline Response $\times$ Ant/Post & 3,39 & $4.90 * *$ & 3,39 & $10.45 * * *$ \\
\hline Response $\times$ Lateral & 2,26 & $9.45 * * *$ & 2,26 & $6.04 * * *$ \\
\hline Response $\times$ Ant/Post & & & & \\
\hline$\times$ Lateral & 6,78 & $5.25 * * *$ & - & - \\
\hline
\end{tabular}

Note. Dashes represent nonsignificant results. Ant/Post $=$ anterior-posterior dimension.

$* p<.10 . \quad * * p<.05$. $* * * p<.01$. electrodes, $F(1,14)=48.03, p<.01$. The Response Type $\times$ Lateral Dimension interaction was also present when the data were subjected to the same ANOVA after amplitude normalization, $F(2,28)=6.76, p<.01$, suggesting a topographical difference between the late ERPs on correct and erroneous trials.

\section{Bifrontopolar Group}

As can be seen in Figure 2, patients with bifrontopolar and orbitofrontal lesions as well as the corresponding agematched control group showed an ERN after incorrect responses. A smaller negative wave of similar latency was also elicited on correct trials (incompatible as well as compatible) in both groups. In the late time range, the error positivity $(\mathrm{Pe})$ is visible for erroneous but not for correct responses in the patients as well as the controls. The peak latencies of the ERN at $\mathrm{FCz}$ did not differ significantly between the patient $(M=80.0 \mathrm{~ms}, S E M=6.3)$ and the control $(M=79.1 \mathrm{~ms}$, SEM $=6.0)$ groups $(p>.91)$.

The ERN. The results of the ANOVA examining the effect of Response Type in the bifrontopolar and control groups can be found in Table 3 (middle panel). No significant main effect of Group nor a Group $\times$ Response Type interaction were observed, suggesting that the early electrophysiological correlates of response monitoring did not differ between the groups. Several significant interactions of Response Type and topographical factors were investigated by post hoc comparisons, revealing that the ERP difference between erroneous and correct incompatible trials was largest at the midline electrodes $\mathrm{FCz}, F(1,13)=16.25, p<.01$, and $\mathrm{Cz}, F(1,13)=24.95, p<.01$. The same ANOVA performed on amplitude-normalized data gave rise to the interactions Response Type $\times$ Anterior-Posterior Dimen-

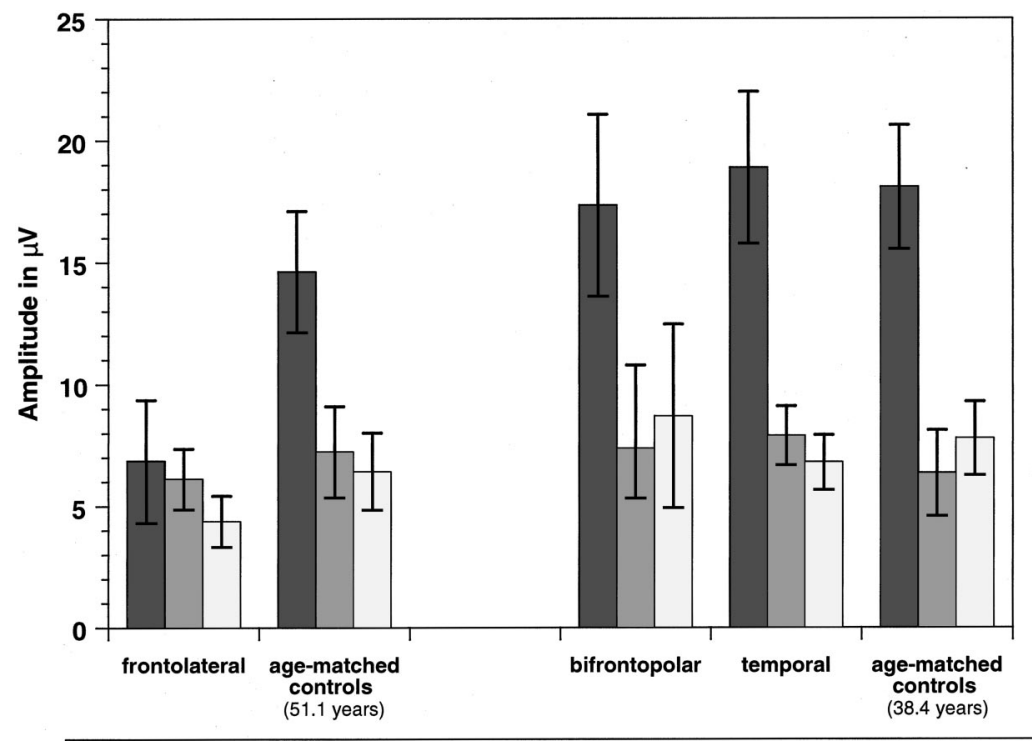

incompatible error $\square$ incompatible correct $\square$ compatible correct

Figure 4. Peak amplitudes of the negativity following incompatible erroneous (the error-related negativity) and correct responses at FCz for all groups. 
sion, $F(3,39)=6.22, p<.01$, Response Type $\times$ Lateral Dimension, $F(2,26)=13.50, p<.01$, and Response Type $\times$ Anterior-Posterior $\times$ Lateral Dimension, $F(6$, $78)=8.49, p<.01$, suggesting a topographical difference in ERP scalp distribution between correct and incorrect responses. The ANOVA examining the influence of compatibility on the ERPs following correct responses revealed neither amplitude nor topography differences and no Group effects.

Peak amplitudes at $F C z$. The ANOVA contrasting the peak amplitudes (cf. Figure 4) of the negativity on correct and incorrect incompatible trials revealed a main effect of Response Type, $F(2,26)=18.42 ; p<.01$. There was no main effect of and no interaction with the Group factor. In a further ANOVA contrasting correct incompatible and compatible trials, no main effects or interactions of the factors Group and Compatibility were obtained. This supports the above-mentioned findings that the early electrophysiological correlates of response monitoring did not differ between these groups.

The $P e$. In the late time window, in addition to the main effect of Response Type, a Response Type $\times$ AnteriorPosterior Dimension $\times$ Group was obtained. To test whether this interaction reflected a group difference in the Pe, separate follow-up ANOVAs for correct and erroneous trials were performed. There was a trend for a Group $\times$ Anterior-Posterior Dimension interaction only for erroneous trials, $F(3,39)=3.77, p<.06$; no such interaction was obtained for correct trials $(p>.86)$. The same interaction was significant when amplitude-normalized data from error trials were subjected to the same ANOVA, $F(3,39)=4.36$, $p<.05$, suggesting a topographical difference in scalp distribution of the Pe between the groups. As can be seen in Figure 5, depicting the mean amplitude in the late time window at midline electrodes, the Pe was focused more anteriorly in the bifrontopolar patients than in the controls.

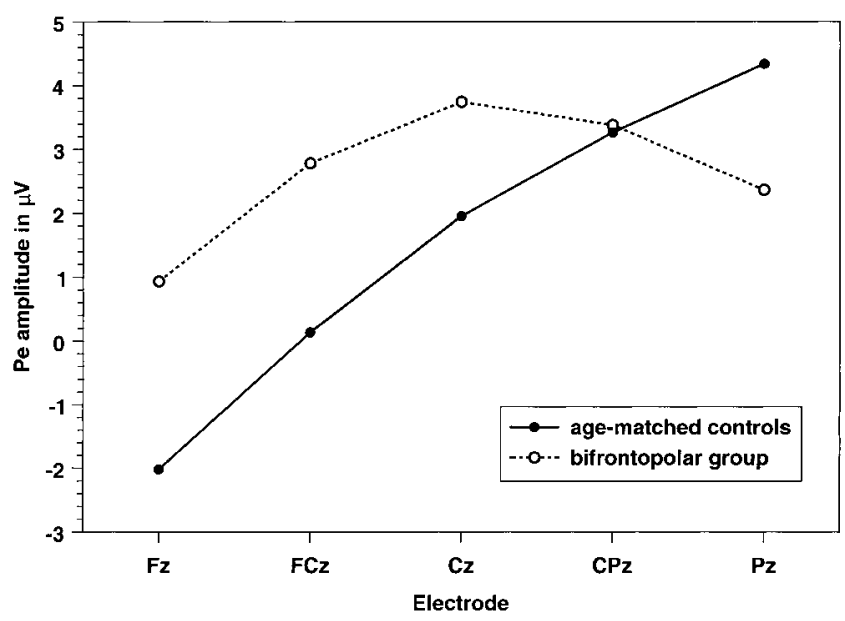

Figure 5. Mean amplitudes of the error positivity Pe at midline electrodes in the bifrontopolar and the age-matched control group.

\section{Temporal Group}

In patients with temporal lobe lesions, errors also elicited an ERN as well as a Pe (Figure 2). The latency of the ERN at $\mathrm{FCz}$ amounted to $M=70.7 \mathrm{~ms}(S E M=8.5)$ and did not differ significantly from the peak latency in the corresponding control group $(p>.58)$. As in the controls, at $\mathrm{FCz}$ a smaller negative deflection similar to the ERN was observed for correct trials.

The ERN. The mixed ANOVA testing the effects of Response Type in the temporal and the control groups gave rise to a main effect of Response Type and interactions of Response Type with both topographical factors (cf. Table 3, lower panel). No Response Type $\times$ Group interaction was found, suggesting that the groups did not differ with respect to the ERPs for correct and incorrect responses. Follow-up comparisons were performed to further investigate the interactions with the topographical factors. They revealed that the amplitude difference between the ERPs on correct incompatible trials and the ERN was largest at $\mathrm{FCz}, F(1$, $13)=8.14, p<.05$, and Fz, $F(1,13)=11.78, p<.01$. When the ANOVA was performed on the data after amplitude normalization, the same topographical interactions were found, reflecting differences in scalp distribution of the ERPs for correct and incorrect incompatible trials: Response $\times$ Anterior-Posterior Dimension, $F(3,39)=5.92$, $p<.01$; Response $\times$ Lateral Dimension, $F(2,26)=8.45$, $p<.01$; Response $\times$ Anterior-Posterior Dimension $\times$ Lateral Dimension, $F(6,78)=4.51, p<.01$. The ANOVA contrasting incompatible and compatible correct trials did not reveal any significant main effects of Group or Response Type and no interactions with these factors, such that no effect can be claimed of Compatibility on response monitoring of correct responses.

Peak amplitudes at FCZ. The peak amplitude data at $\mathrm{FCz}$ for temporal patients and their controls, measured as the difference of the preceding positive deflection and the negative deflection after the response, are visible in Figure 4. No significant group differences were found when contrasting correct and erroneous incompatible responses. As expected, there was a main effect of Response Type, $F(1,13)=27.04, p<.01$, reflecting that the ERN is also significantly larger in temporal lesions than the negativity following the correct responses. The ANOVA contrasting compatible and incompatible correct trials did not reveal significant effects or interactions of Group or Compatibility $(p>.80)$.

The Pe. As shown in Table 3 (lower panel), in the late time window the ANOVA examining correct and erroneous incompatible trials revealed no main effect of and no interactions with the factor Group. The main effect of Response Type suggests that temporal lesion patients also had a Pe. The interactions of Response type with Lateral Dimension and Anterior-Posterior Dimension factors were investigated in follow-up comparisons, revealing that the largest difference between correct and incorrect trials was at parietal electrodes, with the maximum at Pz, $F(1,13)=51.31, p<$ .01. The interactions of Response Type and topographical factors were also obtained for amplitude-normalized data: 
Response $\times$ Anterior-Posterior, $F(3,39)=9.25, p<.015$; Response $\times$ Lateral Dimension, $F(2,26)=6.35, p<.01$; Response $\times$ Anterior-Posterior $\times$ Lateral Dimension, $F(6$, 78) $=2.42, p<.05$.

\section{Discussion}

The results in the lateral frontal cortex group replicated and extended the findings by Gehring and Knight (2000): In the time window of the ERN, the ERPs on correct and incorrect trials did not differ. In addition, our results show a smaller Pe amplitude in the patient group than in matched controls. In contrast to Gehring and Knight (2000), who reported an amplitude increase for the negativity following correct responses and an unaffected ERN, our results suggest that the ERN amplitude was reduced, whereas the amplitude of the negativity on correct trials was comparable to the one in controls. When interpreting these findings, one first has to find whether the negativities in response-locked ERPs to correct and incorrect responses reflect similar processes or not (cf. Coles et al., 2001). If yes, the amplitude difference between both conditions is the most critical aspect of the results across groups. If, however, the scalp topographies of the ERPs differ between correct and incorrect responses, at least partly different underlying neural processes must be assumed. Then, only the absolute amplitude of the ERN can be compared between groups; that is, it would be very difficult-if not impossible-to interpret lesion effects on the amplitude difference between correct and error trials. In our data set, we found topographical differences between the two response types in all groups except for the frontolateral lesion patients and the older control group. Thus, one cannot claim that neural processes immediately after the response differ qualitatively with respect to the response type in these two groups. What process could be reflected in an ERN-like wave that is also present after correct responses? One could speculate that this process is an ongoing conflict about whether the response was correct or not. This view was indirectly supported by a study demonstrating an increase of the ERN amplitude in late responses, in which higher conflict about the correct response can be assumed (Luu, Flaisch, \& Tucker, 2000). Within the error-detection framework, this would be the case when the comparison process is disturbed (see below). In the nomenclature of the response conflict model, the response conflict would continue even after the response and would change to "post-response conflict" (Carter, 2001). One may speculate further that the time needed to resolve (pre-) response conflicts depends on the type of task. It seems conceivable that the task used by Gehring and Knight (2000; a cue determining the target had to be held in memory and the correct task set had to be selected for the correct response) involved a larger working memory load and more task-set management processes than the flanker task as used in the present study. This could explain why (postresponse) conflict and its putative ERP correlate- the negativity on correct responses - were higher in the Gehring and Knight study. This view could also explain why, in the frontolateral patients, the negativity on correct incompatible trials was larger than in correct compatible ones (which do not involve high response conflict). An explanation derived from the conflict-monitoring theory for this latter finding in the patient group could be suggested: It might be due to a reduced attentional contrast between the central target arrow and the flankers, resulting in increased response conflict. In other words, the frontolateral patients might have been less able to focus on the target stimulus such that the response priming from flanker signals would be enhanced. On incompatible trials, the response priming from the flankers would compete with the correct response, whereas on compatible trials, the flanker signal would facilitate the correct response and reduce conflict. Alternatively, one might also speculate that in patients with lateral frontal lesions the response conflict persisted longer than in younger patients and controls rather than increasing because of problems with attentional contrast. This could also explain why we did not find any amplitude differences of the negativity on correct compatible and correct incompatible trials in the younger groups: In these participants, the conflict might have been completely resolved before the response was issued.

It seems that unilateral lesions of the lateral frontal cortex render the generators of the ERN unable to distinguish between correct and erroneous responses. Interestingly, the ERN scalp distribution did not differ between patients and controls; specifically, it was not changed at lateral frontal electrodes (covering the lesion site). This supports the notion that the lateral frontal cortex is not directly involved in the electrical generation of the ERN but has rather an indirect, modulating effect on error detection. How can detection of errors be disrupted? As pointed out by Coles et al. (2001), either the representation of the correct response or the representation of the actually performed response may be disturbed. The representation of the correct response arises from an ongoing evaluation of the stimuli and application of the rules from the currently relevant task set. It is conceivable that the lateral prefrontal cortex might be involved in several ways: The relevant task set must be maintained and the stimulus representations must be manipulated according to the mapping rules. Furthermore, the resulting representation of the correct response must be maintained for comparison with the actually performed response. The lateral prefrontal cortex has been shown to be engaged in maintenance and manipulation of information (D’Esposito et al., 2000; Goldman-Rakic, 1996; Gruber \& von Cramon, 2001; Müller et al., in press) and in task-set related management functions (MacDonald et al., 2000; Ullsperger \& von Cramon, 2001; Zysset et al., 2001), which may be disturbed when the lateral prefrontal cortex is damaged. The prolongation of the RTs as well as the increase in late responses in the frontolateral group could reflect difficulties in applying the stimulus-response mapping rules (i.e., the task set) and in establishing the correct response representation. An incomplete representation of the correct response would make error detection difficult, which is reflected in a lower amplitude of the ERN, and may also be accompanied by an ERN-like wave on correct trials (Coles et al., 2001; Scheffers \& Coles, 2000). 
If errors cannot be properly detected, the alerting error signal is less reliable, and resulting processes such as awareness and assessment of the error must also be affected. This could explain why the Pe amplitude is reduced in the frontolateral group. Consistent with these considerations, Gehring and Knight (2000) reported that remedial actions after errors were partly disturbed in patients with lateral prefrontal lesions. However, the mere presence of the Pe indicates that errors must have been detected to some extent-though less reliably than in healthy controls. One explanation might be the unilaterality of the lateral prefrontal lesions, such that the error-detection system received input from at least one healthy frontal lobe and could function on a suboptimal level. It would be interesting to follow the question of whether bilateral frontal lesions have even larger effects (i.e., abolition of the Pe). We did not find significant differences in performance according to whether the erroneous response was ipsi- or contralateral to the lesion. It might be interesting to investigate in future studies whether the ERN results vary with the laterality of stimuli and responses.

Our data suggest that lesions in frontopolar and anterior orbitofrontal cortices as well as in temporal cortices do not significantly interfere with performance monitoring. It seems that the frontomedian generator of the ERN was not influenced by these lesions. Only the maximum of the Pe was localized more anteriorly in the bifrontopolar group as compared with controls. Also, behavioral performance did not differ between the young patient groups and their healthy controls. This finding was expected for the temporal group and supports the idea that the temporal lobes are not largely involved in performance monitoring. ${ }^{1}$

However, the findings for the patients with bifrontopolarorbitofrontal lesions were not entirely in accordance with the hypotheses. As pointed out at the beginning of this article, previous research has suggested a role of the orbitofrontal cortex regarding the affective and motivational input to performance monitoring (e.g., Bechara et al., 1997, 1998; Luu \& Tucker, 2001; Tucker et al., 1999). However, generation of the ERN was not affected, and the maximum of the Pe was only shifted anteriorly but not significantly reduced (Figure 5). Although a topographical difference suggests at least partly different underlying neuronal processes, it can only be speculated that different scalp distribution of the Pe could reflect a change in the emotional assessment of the committed errors. The presence of an unaffected ERN suggests that the generation of this component is not strongly dependent on input from the anterior orbitofrontal cortex. It is interesting to note that Swick et al. (2001) reported an abolition of the ERN in three patients with lesions of the orbitofrontal cortex, which is not consistent with our findings. However, it seemed that in their patients, lesions extended into the pregenual ACC and subcallosal area (BA 24a, 24b, 25). In contrast, the entire anterior cingulate as well as subcallosal cortex was spared in all patients who participated in the present study. Lesions of the rostral, particularly pregenual ACC and subcallosal cortex, have been shown to reduce or abolish the ERN (Segalowitz, Davies, Pailing, \& Stemmer, 2000; Swick et al., 2001; Swick \& Turken, 2000). Thus, anatomical and functional integrity of the emotional subdivision of the ACC itself (cf. Bush, Luu, \& Posner, 2000) seems to play an important role for the generation of the ERN. According to primate studies, limbic input to the caudal ACC, including the CMA, is indirect through the pregenual ACC and subcallosal area (BA 24a, 24b, 25; Morecraft \& van Hoesen, 1998; Paus, 2001). Our results suggest that the rostral ACC rather than the orbitofrontal cortex may be the most relevant structure for emotional input to the error-detection system. Future studies should address whether the influence of the orbitofrontal cortex on the awareness and assessment of errors and the consequences on motivation, affect, and possibly long-term strategic adjustments is larger when accuracy is directly coupled to reward and punishment (Bechara et al., 1998; Dikman \& Allen, 2000; Gehring et al., 1993).

Finally, in the young patients as well as in their controls we did not find ERP differences between compatible and incompatible correct responses. Performance data suggest that the task was slightly easier for the young groups than for the older participants, particularly for the frontolateral patients. In other words, they might have had enough time to resolve response conflict before the correct response was issued. Therefore, response conflict or uncertainty probably did not continue over the response and did not influence response-locked ERPs.

\section{Conclusion}

The present study provides further support for the strong functional interconnection of the lateral prefrontal cortex and the cingulate motor area in monitoring behavior. In addition, a third system involved in the generation of the $\mathrm{Pe}$ must be assumed.

Furthermore, it was demonstrated that frontopolar and anterior orbitofrontal as well as temporal cortices have little influence on error detection and on its early electrophysiological correlate, the ERN. A hint for a role of the orbitofrontal cortex in emotional assessment of errors was provided by topographic changes of the Pe.

However, it remains unclear why the performance of patients whose electrophysiological correlates of error processing are disturbed shows only minor or no changes, as was the case in this and other patient studies investigating performance monitoring (Gehring et al., 2000; Gehring \& Knight, 2000; Segalowitz et al., 2000; Swick et al, 2001). The investigation of error awareness, its behavioral reflection, and its relationship to the Pe will be important topics to study for a better understanding of how people make and correct errors. In sum, the results suggest that performance

\footnotetext{
${ }^{1}$ Note that the temporal lesions did not affect the temporoparietal junction area, which was shown to be important for the generation of the P3b (e.g., Knight \& Scabini, 1998). Therefore, it seems plausible that the $\mathrm{Pe}-\mathrm{a}$ component with similarities to the P3b (Davies et al., 2001; Falkenstein et al., 2000)—was unaffected in these patients.
} 
monitoring is a very complex set of processes, involving a widespread network of brain structures.

\section{References}

Barbas, H., \& Pandya, D. N. (1989). Architecture and intrinsic connections of the prefrontal cortex in the rhesus monkey. Journal of Comparative Neurology, 289, 353-375.

Bates, J. F., \& Goldman-Rakic, P. S. (1993). Prefrontal connections of medial motor areas in the rhesus monkey. Journal of Comparative Neurology, 336, 211-228.

Bechara, A., Damasio, H., Tranel, D., \& Anderson, S. W. (1998). Dissociation of working memory from decision making within the human prefrontal cortex. The Journal of Neuroscience, 18, $428-437$.

Bechara, A., Damasio, H., Tranel, D., \& Damasio, A. R. (1997, February 28). Deciding advantageously before knowing the advantageous strategy. Science, 275, 1293-1295.

Bechara, A., Tranel, D., Damasio, H., \& Damasio, A. R. (1996). Failure to respond autonomically to anticipated future outcomes following damage to prefrontal cortex. Cerebral Cortex, 6, 215-225.

Botvinick, M. M., Braver, T. S., Barch, D. M., Carter, C. S., \& Cohen, J. D. (2001). Conflict monitoring and cognitive control. Psychological Review, 108, 624-652.

Bush, G., Luu, P., \& Posner, M. I. (2000). Cognitive and emotional influences in anterior cingulate cortex. Trends in Cognitive Sciences, 4, 215-222.

Carter, C. S. (2001, June). Modular functional contributions of medial and lateral frontal cortex to executive control: Evidence from event-related fMRI and ERP. Paper presented at TENNET XII, Montreal, Quebec, Canada.

Carter, C. S., Braver, T. S., Barch, D. M., Botvinick, M. M., Noll, D., \& Cohen, J. D. (1998, May 1). Anterior cingulate cortex, error detection, and the online monitoring of performance. Science, 280, 747-749.

Carter, C. S., MacDonald, A. M., III, Botvinick, M., Ross, L. L., Stenger, V. A., Noll, D., \& Cohen, J. D. (2000). Parsing executive processes: Strategic vs. evaluative functions of the anterior cingulate cortex. Proceedings of the National Academy of Sciences, 97, 1944-1948.

Coles, M. G. H., Scheffers, M. K., \& Holroyd, C. (1998). Berger's dream? The error-related negativity and modern cognitive psychophysiology. In H. Witte, U. Zwiener, B. Schack, \& A. Döring (Eds.), Quantitative and topological EEG and MEG analysis (pp. 96-102). Jena-Erlangen, Germany: Druckhaus Mayer Verlag.

Coles, M. G. H., Scheffers, M. K., \& Holroyd, C. B. (2001). Why is there an ERN or Ne on correct trials? Response representations, stimulus-related components, and the theory of errorprocessing. Biological Psychology, 56, 173-189.

Davies, P. L., Segalowitz, S. J., Dywan, J., \& Pailing, P. E. (2001) Error-negativity and positivity as they relate to other ERP indices of attentional control and stimulus processing. Biological Psychology, 56, 191-206.

Dehaene, S., Posner, M. I., \& Tucker, D. M. (1994). Localization of a neural system for error detection and compensation. Psychological Science, 5, 303-305.

D'Esposito, M., Postle, B. R., \& Rypma, B. (2000). Prefrontal cortical contributions to working memory: Evidence from event-related fMRI studies [Electronic version]. Experimental Brain Research, 133, 3-11.

Dikman, Z. V., \& Allen, J. J. B. (2000). Error monitoring during reward and avoidance learning in high- and low-socialized individuals. Psychophysiology, 37, 43-45.
Falkenstein, M., Hielscher, H., Dziobek, I., Schwarzenau, P., Hoormann, J., Sundermann, B., \& Hohnsbein, J. (2001). Action monitoring, error detection, and the basal ganglia: An ERP study. NeuroReport, 12, 157-161.

Falkenstein, M., Hohnsbein, J., Hoormann, J., \& Blanke, L. (1990). Effects of errors in choice reaction tasks on the ERP under focused and divided attention. In C. H. M. Brunia, A. W. K. Gaillard, \& A. Kok (Eds.), Psychophysiological brain research (pp. 192-195). Tilburg, the Netherlands: Tilburg University Press.

Falkenstein, M., Hoormann, J., Christ, S., \& Hohnsbein, J. (2000). ERP components on reaction errors and their functional significance: A tutorial. Biological Psychology, 51, 87-107.

Gehring, W. J., Goss, B., Coles, M. G. H., Meyer, D. E., \& Donchin, E. (1993). A neural system for error detection and compensation. Psychological Science, 4, 385-390.

Gehring, W. J., Himle, J., \& Nisenson, L. G. (2000). Actionmonitoring dysfunction in obsessive-compulsive disorder. Psychological Science, 11, 1-6.

Gehring, W. J., \& Knight, R. T. (2000). Prefrontal-cingulate interactions in performance monitoring. Nature Neuroscience, 3, $516-520$

Goldman-Rakic, P. S. (1996). Regional and cellular fractionation of working memory. Proceedings of the National Academy of Sciences, 93, 13473-13480.

Gratton, G., Coles, M. G. H., \& Donchin, E. (1983). A new method for off-line removal of ocular artifact. Electroencephalography and Clinical Neurophysiology, 55, 468-484.

Gruber, O., \& von Cramon, D. Y. (2001). Domain-specific distribution of working memory processes along human prefrontal and parietal cortices: A functional magnetic resonance imaging study. Neuroscience Letters, 297, 29-32.

Hazeltine, E., Poldrack, R., \& Gabrieli, J. D. E. (2000). Neural activation during response competition. Journal of Cognitive Neuroscience, 12(Suppl. 2), 118-129.

Hohnsbein, J., Falkenstein, M., \& Hoormann, J. (1998). Performance differences in reaction tasks are reflected in event-related brain potentials (ERPs). Ergonomics, 41, 622-633.

Holroyd, C. B. (2001). Reinforcement learning and the errorrelated negativity: A computational and neurophysiological investigation. Unpublished doctoral dissertation, University of Illinois at Urbana-Champaign.

Holroyd, C. B., Dien, J., \& Coles, M. G. H. (1998). Error-related scalp potentials elicited by hand and foot movements: Evidence for an output-independent error-processing system in humans. Neuroscience Letters, 242, 65-68.

Holroyd, C. B., Reichler, J., \& Coles, M. G. H. (1999). Is the error-related negativity generated by a dopaminergic error signal for reinforcement learning? Hypothesis and model. Journal of Cognitive Neuroscience, 11, 45.

Huynh, H., \& Feldt, L. S. (1970). Conditions under which mean square ratio repeated measurements designs have exact $F$ distributions. Journal of the American Statistical Association, 65, 1582-1589.

Kiehl, K. A., Liddle, P. F., \& Hopfinger, J. B. (2000). Error processing and the rostral anterior cingulate: An event-related fMRI study. Psychophysiology, 37, 216-223.

Knight, R. T., \& Scabini, D. (1998). Anatomic bases of eventrelated potentials and their relationship to novelty detection in humans. Journal of Clinical Neurophysiology, 15, 3-13.

Kopp, B., Rist, F., \& Mattler, U. (1996). N200 in the flanker task as a neurobehavioral tool for investigating executive control. Psychophysiology, 33, 282-294. 
Luu, P., Collins, P., \& Tucker, D. M. (2000). Mood, personality, and self-monitoring: Negative affect and emotionality in relation to frontal lobe mechanisms of error monitoring. Journal of Experimental Psychology: General, 129, 43-60.

Luu, P., Flaisch, T., \& Tucker, D. M. (2000). Medial frontal cortex in action monitoring. Journal of Neuroscience, 20, 464-469.

Luu, P., \& Tucker, D. M. (2001). Regulating action: Alternating activation of midline frontal and motor cortical networks. Clinical Neurophysiology 112, 1295-1306.

MacDonald, A. W., III, Cohen, J. D., Stenger, V. A., \& Carter, C. S. (2000, June 9). Dissociating the role of the dorsolateral prefrontal and anterior cingulate cortex in cognitive control. Science, 288, 1835-1838.

McCarthy, G., \& Wood, C. C. (1985). Scalp distributions of event-related potentials: An ambiguity associated with analysis of variance models. Electroencephalography and Clinical Neurophysiology, 62, 203-208.

Morecraft, R. J., \& van Hoesen, G. W. (1998). Convergence of limbic input to the cingulate motor cortex in the rhesus monkey. Brain Research Bulletin, 45, 209-232.

Morgan, J. M., Wenzl, M., Lang, W., Lindinger, G., \& Deeke, L. (1992). Frontocentral DC-potential shifts predicting behavior with or without a motor task. Electroencephalography and Clinical Neurophysiology, 83, 378-388.

Müller, N. G., Machado, L., \& Knight, R. T. (in press) Contributions of subregions of the prefrontal cortex to working memory: Evidence from brain lesions in humans. Journal of Cognitive Neuroscience.

Nieuwenhuis, S., Ridderinkhof, K. R., Blom, J., Band, G. P. H., \& Kok, A. (2001). Error-related brain potentials are differentially related to awareness of response errors: Evidence from an antisaccade task. Psychophysiology, 38, 752-760.

Paus, T. (2001) Primate anterior cingulate cortex: Where motor control, drive and cognition interface. Nature Reviews Neuroscience, 2, 417-424.

Paus, T., Castro-Alamancos, M., \& Petrides, M. (2000). Corticocortical connectivity of the human mid-dorsolateral frontal cortex and its modulation by repetitive transcranial magnetic stimulation: A combined TMS/PET study. NeuroImage, 11(Suppl.), S765.

Perrin, F., Pernier, J., Bertrand, O., \& Echallier, J. F. (1989). Spherical splines for scalp potential and current density mapping. Electroencephalography and Clinical Neurophysiology, 72, 184-187.

Petrides, M. (1996, October 29). Specialized systems for the processing of mnemonic information within the primate frontal cortex. Philosophical Transactions of the Royal Society of London. Series B: Biological Sciences, 351, 1455-1462.

Pfeifer, E. (1993). IPCM-Iterative PCA correction method. A new method for the correction of ocular artifacts in ERP-data. Psychophysiology, 30, 51.

Rogers, R. D., \& Monsell, S. (1995). Costs of a predictable switch between simple cognitive tasks. Journal of Experimental Psychology: General, 124, 207-231.

Scheffers, M. K., \& Coles, M. G. H. (2000). Performance monitoring in a confusing world: Error-related brain activity, judgments of response accuracy, and types of errors. Journal of Experimental Psychology: Human Perception and Performance, 26, 141-151.

Schultz, W., \& Dickinson, A. (2000). Neuronal coding of prediction errors. Annual Review of Neuroscience, 23, 473-500.

Segalowitz, S. J., Davies, P. L., Pailing, P. E., \& Stemmer, B. (2000). Error-related ERP responses: Error detection or beyond? Psychophysiology, 37(Suppl. 1), S10.

Sharbrough, F., Chatrian, G., Lesser, R. P., Lüders, H., Nuwer, M., \& Picton, T. W. (1990). Guidelines for standard electrode position nomenclature. Bloomfield, IN: American EEG Society.

Swick, D., \& Turken, A. U. (2000). Neuropsychological perspective on error monitoring and response selection in the anterior cingulate cortex. In W. Mitner \& M. G. H. Coles (Eds.), Executive control, errors, and the brain 2000 (p. 25). Jena, Germany: Friedrich-Schiller-Universität Jena.

Swick, D., Turken, A. U., Larsen, J., Roxby, C., Kopelovich, J. C. S., Jovanovich, J., \& Miller, K. M. (2001). Anterior cingulate cortex: Error monitoring or conflict monitoring? Journal of Cognitive Neuroscience, 13(Suppl. 1), S72.

Tucker, D. M., Hartry-Speiser, A., McDougal, L., Luu, P., \& deGrandpre, D. (1999). Mood and spatial memory: Emotion and right hemisphere contribution to spatial cognition. Biological Psychology, 50, 103-125.

Ullsperger, M., \& von Cramon, D. Y. (2001). Subprocesses of performance monitoring: A dissociation of error processing and response competition revealed by event-related fMRI and ERPs. NeuroImage, 14, 1387-1401.

Zysset, S., Müller, K, Lohmann, G., \& von Cramon, D. Y. (2001). Color-word matching Stroop task: Separating interference and response conflict. NeuroImage, 13, 29-36.

Received August 27, 2001

Revision received February 11, 2002

Accepted April 11, 2002 